\title{
Pengaruh Leader Member Exchange Terhadap Kepuasan Kerja Karyawan
}

\author{
Rizka Nurhasti Agusta Harahap ${ }^{1 *}$ dan Sholihati Amalia ${ }^{2}$ \\ ${ }^{1}$ Jurusan Administrasi Niaga, Politeknik Negeri Bandung, Indonesia \\ ${ }^{2}$ Jurusan Administrasi Niaga, Politeknik Negeri Bandung, Indonesia
}

\begin{abstract}
:
This research aims to determine the influence of leader member exchange to employee job satisfaction in PT Sandy Globalindo. Leader member exchange is variable $(X)$ and job satisfaction is a variable $(Y)$. The research method that used is the analytic method with cross sectional approach. The sample in this research is 101 employees. Descriptive analysis showed that the leader member exchange in PT Sandy Globalindo in the category enough with a mean of 2.91 and job satisfaction of employees at PT Sandy Globalindo in the category enough with a mean of 3.04. Simple linear regression test results indicates that the variable leader member exchange impact of $38.2 \%$ on job satisfaction while amounting to $61.8 \%$ of job satisfaction influenced by other things that are not explained in this research. Therefore, it can be concluded that there are significant influence of leader member exchange to employee job satisfaction in PT Sandy Globalindo.
\end{abstract}

Keywords: job satisfaction, leader member exchange

\section{PENDAHULUAN}

Sumber daya organisasi merupakan salah satu aset paling berharga perusahaan yang dapat membantu mencapai tujuannya. Selain itu, sumber daya manusia merupakan salah satu faktor terpenting yang membantu perusahaan memenangkan persaingan. Oleh sebab itu, sumber daya manusia harus dikelola dengan baik. Pemimpin berperan dan bertanggung jawab dalam proses pengelolaan sumber daya tersebut.

Peran pemimpin dalam sebuah organisasi tidak hanya semata-mata memerintah bawahannya tetapi diperlukan hubungan yang baik antara atasan dan bawahan untuk mengoptimalkan fungsi sumber daya manusia yang ada. Pada umumnya, atasan memiliki peran mengembangkan, memotivasi dan

\footnotetext{
*Email korespondensi:

Rizka Nurhasti Agusta Harahap

rizkahurhastuti@ymail.com
}

membimbing bawahannya. Namun dalam kenyataannya, perlakuan atasan terhadap bawahan berbeda satu dengan yang lainnya.

Faktor tersebut menyebabkan pegawai tidak merasa diperhatikan dan merasa tidak puas dengan pekerjaannya dalam perusahaan, sehingga pegawai memutuskan untuk mengundurkan diri dan memilih pekerjaan di tempat lain. Sedangkan keberlangsungan kegiatan perusahaan tentu saja bergantung kepada sumber daya manusia yang ada didalamnya. Jika para pegawai merasa tidak puas dengan pekerjaannya dan memilih untuk mengundurkan diri, maka kegiatan operasional perusahaan tidak akan berjalan dengan baik.

\section{Identifikasi Masalah}

Berdasarkan uraian latar belakang diatas, identifikasi masalah adalah sebagai berikut: 
1. Bagaimana leader member exchange di PT Sandy Globalindo.

2. Bagaimana kepuasan kerja karyawan di PT Sandy Globalindo.

3. Bagaimana pengaruh leader member exchange terhadap kepuasan kerja karyawan di PT Sandy Globalindo.

\section{Tujuan Penelitian}

Berdasarkan identifikasi masalah yang dipaparkan diatas maka tujuan penelitian ini dirumuskan:

1. Untuk mengetahui leader member exchange di PT Sandy Globalindo.

2. Untuk mengetahui kepuasan kerja karyawan di PT Sandy Globalindo.

3. Untuk mengetahui pengaruh leader member exchange terhadap kepuasan kerja karyawan di PT Sandy Globalindo.

\section{KAJIAN LITERATUR \\ Leader Member Exchange (LMX)}

Teori pertukaran pemimpin-anggota (leader member exchange theory) adalah suatu teori yang mendukung penciptaan para pemimpin di dalam kelompok dan di luar kelompok para bawahan dengan status di dalam kelompok yang akan memiliki peringkat kinerja yang lebih tinggi, tingkat perputaran pekerja yang rendah, dan kepuasan kerja yang lebih tinggi (Robbins \& Judge, 2015: 257). Menurut Kreitner dan Kinicki (dalam Wibowo dan Sutanto, 2013: 2), model leader member exchange didasarkan pada asumsi bahwa pemimpin mengembangkan hubungan satu persatu yang unik dengan masing-masing orang yang melapor kepadanya. Biasanya pemimpin cenderung memilih anggota kelompok orang dalam (in-group) karena mereka memiliki berbagai karakteristik kepribadian dan sikap yang mirip dengan pemimpin tersebut atau karena tingkat kompetensi yang lebih tinggi daripada pengikut yang lainnya.

Menurut Graen and Cashman (dalam Prisetyadi, 2011:1) leader member exchange difokuskan pada penilaian terhadap hubungan dan interaksi antara supervisor (atasan) dan bawahan. Tingkat kedekatan dari hubungan antara pimpinan dan bawahan ini yang menunjukkan adanya indikasi dari leader member erchange di perusahaan. Dalam lingkungan perusahaan dimana peran keseluruhan pegawai sangat penting bagi pencapaian tujuan perusahaan, maka sedapat mungkin out-group dalam leader member exchange harus ditekan jumlahnya dan kalau bisa dihilangkan. Jika keseluruhan pegawai dalam sebuah perusahaan termasuk dalam kelompok in-group, maka hambatanhambatan dalam pekerjaan yang dihadapi pegawai bisa terselesaikan dengan baik karena diantara pegawai dan pimpinan mempunyai hubungan komunikasi yang baik.

Menurut Northouse (dalam Mapolisa \& Kurasha, 2013: 324), teori mengenai leader member exchange memberikan beberapa kontribusi yang positif untuk memahami proses kepemimpinan.

a. Teori leader member exchange merupakan teori deskriptif yang kuat.

b. Teori leader member exchange memiliki keunikan karena merupakan satusatunya pendekatan kepemimpinan yang membuat konsep hubungan dua arah (dyadic) inti dari proses kepemimpinan.

c. Teori leader member exchange adalah penting karena mengarahkan perhatian pada peringatan penting bagi para pemimpin.

Sementara itu, Bitmis \& Ergeneli (2012:113) menyimpulkan terdapat empat dimensi dari leader member exchange yaitu:

a. Contribution, didefinisikan sebagai persepsi akan kuantitas, arahan, dan kualitas dari aktivitas yang berorientasi pekerjaan masing-masing anggota terhadap pencapaian tujuan bersama.

b. Loyalty, mengacu pada sejauh mana pemimpin dan anggota saling mendukung satu sama lain terhadap tujuan, tindakan dan karakteristik personal dalam situasi apapun.

c. Affect, artinya rasa saling menyukai antara pemimpin dan pengikut didasarkan pada ketertarikan 
interpersonal (interpersonal attraction) dibandingkan pekerjaan atau nilai profesionalitas

d. Professional respect, mengacu pada persepsi sejauh mana setiap anggota saling membangun reputasi, di dalam dan atau luar organisasi, dalam mengunggulkan bidang pekerjaannya.

\section{Kepuasan Kerja}

Kepuasan kerja adalah tingkat perasaan menyenangkan yang diperoleh dari penilaian pekerjaan seseorang atau pengalaman kerja (Colquitt, LePine, Wesson, 2011:105). Dengan kata lain, kepuasan kerja mencerminkan bagaimana kita merasakan tentang pekerjaan kita dan apa yang kita pikirkan tentang pekerjaan kita. McShane dan Mary (2010:108) memandang kepuasan kerja sebagai evaluasi seseorang atas pekerjaannya dan konteks pekerjaan. Merupakan penilaian terhadap karakteristik pekerjaan, lingkungan kerja, dan pengalaman emosional di pekerjaan yang dirasakan.

Menurut Robbins dan Judge (2015) kepuasan kerja adalah sebuah perasaan positif terhadap pekerjaan yang dihasilkan dari evaluasi atas karakteristikkarakteristiknya. Kreitner dan Kinicki (dalam Wibowo 2015:132) mengemukakkan bahwa kepuasan kerja adalah respon efektif atau emosional terhadap berbagai aspek dari pekerjaan seseorang. Definisi ini menyatakan secara tidak langsung bahwa kepuasan kerja bukanlah merupakan konsep tunggal. Melainkan, orang dapat secara relatif puas dengan satu aspek dari pekerjaannya dan tidak puas dengan satu aspek atau lebih.

Luthans (2005) mengidentifikasi lima dimensi yang terdapat dalam kepuasan kerja, yaitu:

a. Pekerjaan itu sendiri

Kepuasan terhadap pekerjaan itu sendiri dimana perusahaan memberikan tugas yang menarik, kesempatan untuk belajar dan kesempatan untuk menerima tanggung jawab. Kepuasan kerja pun terjadi apabila pekerjaan tersebut memberikan kesempatan individu untuk belajar sesuai dengan minat serta kesempatan untuk bertanggung jawab.

b. Imbalan

Dalam kepuasan terhadap imbalan, sejumlah upah yang diterima bisa dipandang sebagai hal yang dianggap pantas dibandingkan dengan orang lain dalam organisasi. Kepuasan terhadap imbalan merupakan faktor utama untuk mencapai kepuasan kerja sehingga banyak pihak manajemen yang berupaya meningkatkan kerja staf dengan meningkatkan imbalan kerja.

c. Kesempatan promosi

Kesempatan promosi ini merupakan kesempatan untuk meningkatkan posisi pada struktur organisasi. Kepuasan terhadap pangkat sering dikaitkan dengan dengan ketidakpuasan staf terhadap promosi jabatan.

d. Supervisi

Kesempatan untuk maju dalam organisasi bergantung pada kemampuan atasannya untuk memberikan bantuan teknis dan memotivasi. Kepuasan terhadap supervisi menyangkut hubungan antara atasan dan bawahan atas pengawasan yang dilakukan oleh atasan.

e. Rekan Kerja

Kepuasan terhadap rekan kerja menunjukkan seberapa besar rekan kerja memberikan bantuan teknis dan dorongan sosial. Kepuasan teradap rekan kerja merupakan hubungan antara pekerja satu dengan yang lain berkaitan erat dengan kepuasan kerja. Pekerja mengalami ketidakpuasan kerja karena memiliki rekan kerja yang tidak bisa diajak kerjasama.

\section{Hipotesis Penelitian}

Berdasarkan penjelasan mengenai leader member exchange dengan kepuasan kerja karyawan, dapat dibuat hipotesis penelitian sebagai berikut : 
Ho: Tidak terdapat pengaruh yang signifikan antara Leader Member Exchange dengan Kepuasan Kerja Karyawan di PT Sandy Globalindo.

Ha: Terdapat pengaruh yang signifikan antara Leader Member Exchange dengan Kepuasan Kerja Karyawan di PT Sandy Globalindo.

\section{METODE}

Metode penelitian yang digunakan dalam penelitian ini adalah dengan metode analitis dengan pendekatan Cross Sectional. Pendekatan Cross Sectional adalah penelitian yang bersifat eksploratif, deskriptif ataupun eksplanatif. Penelitian Cross Sectional mampu menjelaskan hubungan satu variabel dengan variabel lain pada populasi yang diteliti, menguji keberlakuan suatu model atau rumusan hipotesis serta tingkat perbedaan di antara kelompok sampling pada satu titik waktu tertentu. Dalam penelitian dengan pendekatan Cross Sectional ini peneliti hanya mengobservasi fenomena pada satu titik waktu tertentu (Nurdini, 2006).

Populasi dari penelitian ini ialah karyawan PT Sandy Globalindo yang berjumlah 135 orang. Dengan perhitungan rumus Slovin ukuran sampel minimal yang harus diambil pada penelitian ini yaitu sebanyak 101 orang responden yang diambil secara accidental sampling di PT Sandy Globalindo.

\section{Teknik Pengumpulan Data}

Dalam penelitian ini data yang digunakan berupa data primer dan data sekunder. Data primer adalah sumber data yang langsung memberikan data kepada pengumpul data (Sugiyono, 2012:137). Data primer didapatkan pada dari wawancara dan penyebaran kusioner kepada karyawan PT Sandy Globalindo. Sedangkan data sekunder adalah sumber yang secara tidak langsung memberikan data kepada pengumpul data, misalnya lewat orang lain atau dokumen (Sugiyono, 2012:137).

\section{HASIL DAN PEMBAHASAN Uji Validitas Dan Reliabilitas}

Dalam penelitian ini data yang digunakan berupa data primer dan data sekunder. Data primer adalah sumber data yang langsung memberikan data kepada pengumpul data (Sugiyono, 2012:137). Data primer didapatkan pada dari wawancara dan penyebaran kusioner kepada karyawan PT Sandy Globalindo. Sedangkan data sekunder adalah sumber yang secara tidak langsung memberikan data kepada pengumpul data, misalnya lewat orang lain atau dokumen (Sugiyono, 2012:137).

Pada hasil uji reliabilitas menunjukkan bahwa seluruh pernyataan pada variabel leader member exchange memiliki skor lebih dari 0,30. Maka dari itu, seluruh pernyataan dari variabel leader member exchange dinyatakan valid.

Sedangkan untuk uji validitas variabel kepuasan kerja karyawan menunjukkan bahwa seluruh pernyataan pada variabel kepuasan kerja karyawan memiliki skor lebih dari 0,30 yang berarti valid. Namun, jika dibandingkan dengan tabel reliabilitas terdapat satu pernyataan yang tidak valid yaitu item pernyataan nomor 13. Maka dari itu, untuk penelitian selanjutkan disarankan item tersebut tidak dipakai.

Tabel 1 Data Responden

\begin{tabular}{|c|c|c|c|}
\hline \multirow{4}{*}{$\begin{array}{c}\text { Lama } \\
\text { Bekerja }\end{array}$} & $<1$ tahun & 6 orang & $5,9 \%$ \\
\cline { 2 - 4 } & $1-2$ tahun & 15 orang & $14,9 \%$ \\
\cline { 2 - 4 } & $3-4$ tahun & 42 orang & $41,6 \%$ \\
\cline { 2 - 4 } & $<5$ tahun & 38 orang & $37,6 \%$ \\
\hline \multirow{4}{*}{$\begin{array}{c}\text { Pendidikan } \\
\text { Terakhir }\end{array}$} & SD & 14 orang & $13,9 \%$ \\
\cline { 2 - 4 } & SMP & 22 orang & $21,8 \%$ \\
\cline { 2 - 4 } & SMA & 52 orang & $51,5 \%$ \\
\cline { 2 - 4 } & D1 & 1 orang & $0,9 \%$ \\
\cline { 2 - 4 } & D3 & - & - \\
\cline { 2 - 4 } & D4 orang & $6,9 \%$ \\
\cline { 2 - 4 } & S1 & - & - \\
\hline \multirow{4}{*}{ Umur } & $<20$ tahun & 6 orang & $4,9 \%$ \\
\cline { 2 - 4 } & $21-25$ tahun & 49 orang & $5,9 \%$ \\
\cline { 2 - 4 } & $26-30$ tahun & 33 orang & $32,7 \%$ \\
\cline { 2 - 4 } & $>30$ tahun & 13 orang & $12,9 \%$ \\
\hline
\end{tabular}




\section{Analisis Deskriptif}

Leader member exchange di PT Sandy Globalindo tergolong pada kategori cukup karena nilai mean dari variabel leader member exchange sebesar 2,91 yang berada pada interval 2,61 - 3,40. Standard deviasi variabel leader member exchange menunjukkan angka 0,325 atau sama dengan $11,16 \%$ dari nilai mean dan hal ini menunjukkan variasi jawaban kecil atau sebagian responden menjawab pernyataan dengan jawaban yang relatif sama.

Tabel 2 Leader Member Exchange

\begin{tabular}{|l|c|c|c|c|c|}
\hline & N & Min & Max & Mean & SD \\
\hline $\begin{array}{l}\text { Leader } \\
\text { Member } \\
\text { Exchange }\end{array}$ & 101 & 2 & 4 & 2,91 & 0,325 \\
\hline Contribution & 101 & 2 & 5 & 2,72 & 0,596 \\
\hline Loyalty & 101 & 2 & 3 & 2,89 & 0,333 \\
\hline Affect & 101 & 2 & 4 & 2,89 & 0,350 \\
\hline $\begin{array}{l}\text { Professional } \\
\text { Respect }\end{array}$ & 101 & 2 & 4 & 3,29 & 0,474 \\
\hline
\end{tabular}

Dimensi pertama dari variabel leader member exchange adalah contribution dengan indikator bekerja lebih dari yang tercantum dalam urusan pekerjaan dan bekerja keras untuk pimpinan. Dimensi contribution memiliki rata-rata sebesar 2,72. Diketahui bahwa indikator bekerja lebih dari yang tercantum dalam urusan pekerjaan dan bekerja keras untuk pimpinan memiliki mean di bawah mean dimensi. Hal tersebut memiliki arti bahwa karyawan belum sepenuhnya bekerja lebih dan belum sepenuhnya bekerja keras untuk pimpinan.

Kontribusi (contribution) merupakan jumlah, arahan dan kualitas dari aktivitas yang berorientasi pada pekerjaan (workoriented activity) yang terus menerus dilakukan pegawai untuk mencapai tujuan bersama (Dienesch \& Liden, 1986 dalam Hwa, et al., 2009:166). Hal yang penting dalam penilaian aktivitas yang berorientasi pada pekerjaan adalah kemampuan bawahan untuk mengembangkan tanggung jawab dan menyelesaikan tugas-tugas melebihi job description atau kontrak pekerjaan (Liden \& Maslyn, 1998 dalam Mumma, 2010:19)

Pegawai PT Sandy Globalindo telah berkontribusi kepada pimpinannya. Hal tersebut dapat dilihat dari aktivitas yang dilakukan oleh pegawai yang telah berorientasi pada pekerjaan masing-masing untuk pencapaian tujuan bersama, baik tujuan unit kerja atau tujuan perusahaan maupun tujuan atau target pimpinan mereka. Kesuksesan organisasi dapat tercapai dengan tingginya kontribusi pegawai tersebut (Rachmawati, 2013:60). Namun, kemauan karyawan untuk bekerja lebih dari yang tercantum dalam urusan pekerjaan dan bekerja keras untuk pimpinan yang masih sedang-sedang saja perlu ditingkatkan guna meningkatkan hasil yang lebih baik lagi dan untuk mencapai tujuan bersama maupun perusahaan. Sejauh ini PT Sandy Globalindo telah menerapkan kebijakan untuk memberikan penghargaan berupa uang (pay for performance) bagi pegawai yang berhasil mencapai kinerja yang tinggi. Kebijakan tersebut diharapkan mampu menjadi salah satu motivasi bagi pegawai untuk meningkatkan kontribusi kerjanya bagi perusahaan.

Dimensi kedua dari variabel leader member exchange yaitu loyalty, dimensi tersebut memiliki nilai rata-rata sebesar 2,89 Nilai rata-rata tersebut tergolong dalam kategori cukup. Loyalitas merupakan kesetiaan terhadap seseorang yang konsisten di setiap situasi (Liden \& Maslyn, 1998 dalam Mumma, 2010:19).

Loyalitas yang diberikan pimpinan PT Sandy Globalindo dapat dilihat dari pimpinan membela bawahannya di hadapan orang lain baik dari dalam maupun luar perusahaan, ketika bawahan tersebut melakukan suatu kesalahan yang tidak disengaja. Akan tetapi, pembelaan pimpinan kepada bawahan yang membuat kesalahan yang tidak disengaja masih perlu ditingkatkan. Dari hasil analisis deskriptif dapat disimpulkan bahwa loyalitas yang diberikan pimpinan di PT Sandy Globalindo bernilai cukup, artinya loyalitas tersebut 
sudah diberikan namun belum terus menerus sehingga masih perlu ditingkatkan lagi agar karyawan merasa dirinya dibutuhkan dalam perusahaan sehingga ia pun bersedia bekerja lebih baik lagi untuk mencapai tujuan bersama. Pemimpin harus selalu mendukung terhadap tujuan bawahannya, tindakan dan karakteristik bawahannya dalam situasi apapun selama untuk pencapaian tujuan perusahaan.

Loyalitas dari pimpinan mempengaruhi tingkat kontribusi yang diberikan bawahan kepada pimpinananya (Hwa, et al., 2009:167). Dengan kata lain, tinggi rendahnya kontribusi yang diberikan bawahan kepada pimpinannya dipengaruhi oleh tinggi rendahnya loyalitas yang diberikan pimpinan kepada bawahannya.

Dimensi ketiga dari variabel leader member exchange yaitu affect, dimensi ini memiliki nilai rata-rata sebesar 2,89 yang tergolong kedalam kategori cukup. Beberapa afeksi dalam suatu hubungan dapat memberikan dampak secara personal, contohnya persahabatan (Liden \& Maslyn, 1998 dalam Mumma, 2010:19).

Afeksi yang dimiliki karyawan PT Sandy Globalindo terhadap pimpinannya dapat dilihat dari rasa nyaman yang dirasakan karyawan ketika bekerja sama dengan pimpinannya karena bekerja sama dengan pimpinan merupakan hal yang menyenangkan. Berdasarkan hasil wawancara ada beberapa karyawan yang merasa mempunyai hubungan dekat dengan pimpinan dan ada beberapa karyawan lain yang merasa mempunyai hubungan yang biasa saja bahkan tidak baik. Afeksi dapat menyebabkan suatu perilaku tertentu. Komponen perilaku sikap menjelaskan kemauan untuk berperilaku dengan cara tertentu terhadap seseorang (Robbins \& Judge, 2013:70). Dengan demikian afeksi karyawan PT Sandy Globalindo yang bernilai cukup menunjukkan bahwa pegawai-pegawai tersebut ada yang berperilaku positif dan ada juga yang negatif terhadap pimpinannya.
Dimensi keempat dari variabel leader member exchange ialah professional respect. Dimensi ini memiliki nilai mean tertinggi dari dimensi yang lainnya yaitu sebesar 3,29. Hal tersebut dapat dilihat dari bawahan yang mengagumi juga menghormati pengetahuan, keterampilan profesional, serta kompetensi yang dimiliki pimpinan mengenai pekerjaannya. Persepsi mengenai penghormatan profesional (professional respect) dapat didasarkan pada data historis dari pimpinan langsung setiap pegawai, seperti pengalaman personal antara pimpinan dengan bawahan, komentar yang diberikan orang lain kepada pimpinan baik dari dalam maupun luar perusahaan dan penghargaan serta pencapaian yang telah diterima oleh pimpinan tersebut (Liden \& Maslyn, 1998 dalam Mumma, 2010:19). Maka dari itu dapat disimpulkan bahwa persepsi pegawai terhadap pimpinannya untuk membangun reputasi didalam maupun diluar perusahaan tergolong kedalam kategori cukup. Artinya meskipun pegawai tersebut mempunyai persepsi yang berbedabeda terhadap pimpinannya, mereka tetap menghargai dan menghormati pimpinannya serta membangun reputasi pimpinan baik didalam maupun diluar PT Sandy Globalindo.

\section{Kepuasan Kerja Karyawan}

Kepuasan kerja karyawan di PT Sandy Globalindo tergolong cukup karena nilai mean dari variabel kepuasan kerja karyawan sebesar 3,04 yang berada pada interval 2,61 - 3,40. Standar deviasi variabel kepuasan kerja karyawan menunjukkan angka 0,330 atau sama dengan $10,85 \%$ dari nilai mean dan hal ini menunjukkan variasi jawaban kecil atau sebagian responden menjawab pernyataan dengan jawaban yang relatif sama.

Dimensi pertama dari variabel kepuasan kerja karyawan adalah pekerjaan itu sendiri, memiliki nilai mean sebesar 3,31 yang berada pada interval 2,61 - 3,40 yang artinya karyawan PT Sandy Globalindo cukup merasa puas dengan pekerjaan yang 
dilakukannya. Menurut Madura (2007) untuk dapat bekerja dengan baik, manajer mengandalkan empat jenis keahlian yaitu keahlian konseptual, interpesonal, teknis dan pengambilan keputusan. Dengan hal tersebut maka dapat diketahui pekerjaan yang dilakukan setiap karyawan akan berbedabeda.

Tabel 3 Kepuasan Karyawan

\begin{tabular}{|l|c|c|c|c|c|}
\hline & N & Min & Max & Mean & SD \\
\hline $\begin{array}{l}\text { Kepuasan } \\
\text { Kerja } \\
\text { Karyawan }\end{array}$ & 101 & 2 & 4 & 3,04 & 0,330 \\
$\begin{array}{l}\text { The work } \\
\text { itself }\end{array}$ & 101 & 2 & 4 & 3,31 & 0,484 \\
\hline Pay & 101 & 2 & 5 & 3,88 & 0,707 \\
\hline $\begin{array}{l}\text { Promotion } \\
\text { Opportunity }\end{array}$ & 101 & 2 & 4 & 3,27 & 0,479 \\
\hline Supervision & 101 & 1 & 3 & 2,23 & 0,424 \\
\hline Co-workers & 101 & 2 & 5 & 3,88 & 0,723 \\
\hline
\end{tabular}

Dimensi kedua dari variabel kepuasan kerja karyawan adalah imbalan. Dimensi imbalan tergolong ke dalam kategori baik atau tinggi, karena memiliki rata-rata dimensi sebesar 3,88. Dapat disimpulkan bahwa karyawan PT Sandy Globalindo sudah merasa puas akan imbalan yang mereka dapat. Menurut Sirait (2006) fungsi pemberian imbalan dapat didefinisikan sebagai usaha untuk memberikan balas jasa bagi karyawan yang telah menyumbangkan waktu dan tenaganya bagi terciptanyanya tujuan organisasi. Tidak menutup kemungkinan bagi mereka dikemudian hari untuk mengharapkan imbalah yang lebih lagi.

Dimensi ketiga dari variabel kepuasan kerja adalah kesempatan promosi. dimensi kesempatan promosi tergolong ke dalam kategori cukup, karena memiliki ratarata dimensi sebesar 3,27. Menurut Hutapea dan Thoha (2008) bagi perusahaan yang telah menerapkan sistem yang berbasis kompetensi, perencanaan karir harus disesuaikan dengan persyaratan kompetensi baik itu persyaratan kompetensi untuk pekerjaan maupun persyaratan kompetensi untuk standar kualifikasi karyawan.
Dimensi keempat dari variabel kepuasan kerja adalah supervisi. Dimensi supervisi tergolong ke dalam kategori cukup, karena memiliki rata-rata dimensi sebesar 2,23. Berdasarkan hasil rata-rata tersebut dapat disimpulkan bahwa karyawan PT Sandy Globalindo sudah merasa cukup puas dengan atasannya. Namun alangkah lebih baik jika supervisi ditujukan untuk meningkatkan pengawasan serta perhatian kepada karyawan-karyawannya sehingga mereka merasa dipedulikan, karena hasil wawancara menyatakan bahwa beberapa karyawan merasa dirinya tidak diperhatikan dan dipedulikan oleh pimpinannya. Menurut Boone dan Kurtz (2007) fungsi pengarahan merupakan tanggung jawab vital bagi manajer penyelia. Untuk memenuhi tanggung jawab mereka menyelesaikan pekerjaan melalui orang, para penyelia harus menjadi pemimpin yang efektif. Di samping itu, manajer tingkat menengah dan puncak harus dapat menjadi pemimpin dan motivator yang baik dan mereka harus menciptakan suatu lingkungan yang akan menyuburkan sifat kepemimpinan seperti itu.

Dimensi kelima dari variabel kepuasan kerja adalah rekan kerja. Dimensi rekan kerja tergolong ke dalam kategori baik, karena memiliki rata-rata dimensi sebesar 3,88 yang berarti karyawan PT Sandy Globalindo merasa puas dengan rekan kerjanya yang saling bekerja sama dan membantu satu sama lain. Robbins \& Judge (2015) menyatakan bahwa mereka merasa rekan kerjanya membantu mereka, lebih mungkin terlibat dalam perilaku yang membantu, begitupun sebaliknya.

\section{Analisis Korelasi}

Nilai korelasi antara variabel leader member exchange dan kepuasan kerja karyawan sebesar 0,618 dengan arah hubungan yang positif. Nilai korelasi sebesar 0,618 dengan arah hubungan yang positif termasuk ke dalam interval 0,60 0,799 yang artinya terdapat hubungan positif yang kuat. Nilai korelasi Pearson pada 
menunjukan bahwa hubungan antara leader member exchange dan kepuasan kerja karyawan memiliki tingkat signifikansi sempurna karena Sig 0,000 (jauh lebih kecil dari 0,05). Hal ini dapat dinyatakan bahwa ketika pimpinan meningkatkan leader member exchange, maka secara kepuasan kerja karyawan tersebut akan meningkat

Tabel 4 Uji Korelasi

\begin{tabular}{|c|c|c|c|}
\hline & & $\begin{array}{c}\text { Leader } \\
\text { Member } \\
\text { Exchange } \\
\end{array}$ & $\begin{array}{c}\text { Kepuasan } \\
\text { Kerja }\end{array}$ \\
\hline Leader & $\begin{array}{l}\text { Pearson } \\
\text { Correlation }\end{array}$ & 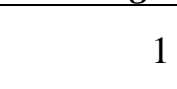 & $0,618^{* *}$ \\
\hline $\begin{array}{l}\text { Member } \\
\text { Exchange }\end{array}$ & Sig. (2-tailed) & & 0,000 \\
\hline & $\mathrm{N}$ & 101 & 101 \\
\hline Kepuasan & $\begin{array}{l}\text { Pearson } \\
\text { Correlation }\end{array}$ & $0,618^{* *}$ & 1 \\
\hline Kerja & Sig. (2-tailed) & 0,000 & \\
\hline & $\mathrm{N}$ & 101 & 101 \\
\hline
\end{tabular}

\section{Uji F}

Uji Anova menghasilkan F sebesar 53,887 dengan tingkat signifikansi sebesar 0,000. Diperoleh pula nilai df1 sebesar 1 dan df2 sebesar 99 maka didapat nilai $F$ tabel sebesar 3,94. Berdasarkan data tersebut, diketahui bahwa besaran nilai $\mathrm{F}$ hitung lebih besar daripada $F$ tabel $(53,887>3,94)$. Selain itu, diketahui pula nilai signifikansi sebesar 0,000 (lebih kecil dari 0,05), sehingga dapat disimpulkan bahwa Ho di tolak dan Ha diterima, yang berarti terdapat pengaruh yang positif dan signifikan antara variabel self leader member exchange terhadap kepuasan kerja karyawan.

Tabel 5 Uji F

\begin{tabular}{|l|l|r|c|c|}
\hline \multicolumn{2}{|l|}{ Model } & \multicolumn{1}{c|}{ df } & F & Sig. \\
\hline \multirow{3}{*}{1} & Regression & 1 & 53,887 & $0,000^{\mathrm{b}}$ \\
\cline { 2 - 5 } & Residual & 99 & & \\
\cline { 2 - 5 } & Total & 100 & & \\
\hline
\end{tabular}

Uji t

Nilai t hitung sebesar 7,815. Dengan rumus $\mathrm{df}=$ jumlah data -1 , atau sebesar
100, maka diperoleh t tabel sebesar 1,660. Berdasarkan hasil tersebut, maka diperoleh nilai $\mathrm{t}$ hitung yang lebih besar dari t tabel $(7,815>1,660)$. Dapat disimpulkan bahwa Ha diterima dan Ho ditolak, hal ini berarti ada pengaruh positif dan signifikan antara leader member exchange terhadap kepuasan kerja karyawan di PT Sandy Globalindo. Dasar pengambilan keputusan probabilitas menurut Sujarweni (2014:103) adalah jika Sig. > 0,05, maka Ho diterima namun jika Sig. < 0,05, maka Ho ditolak. Nilai signifikasni sebesar 0,000 (lebih kecil dari 0,05). Hal tersebut dapat diartikan bahwa model regresi dapat digunakan untuk memprediksi kepuasan kerja karyawan atau dengan kata lain leader member exchange berpengaruh terhadap kepuasan kerja karyawan.

Tabel 6 Uji T

\begin{tabular}{|c|c|c|c|c|c|}
\hline \multirow{2}{*}{ Model } & \multicolumn{2}{|c|}{$\begin{array}{c}\text { Unstand. } \\
\text { Coefficients }\end{array}$} & $\begin{array}{c}\text { Std } \\
\text { Coef } \\
\text { ficie } \\
\text { nts }\end{array}$ & \multirow{2}{*}{ T } & \multirow{2}{*}{ Sig. } \\
\cline { 2 - 5 } & B & $\begin{array}{c}\text { Std. } \\
\text { Err. }\end{array}$ & Beta & & \\
\hline (Constant) & 26,633 & 3,681 & & 7,234 & 0,000 \\
\hline $\begin{array}{l}\text { Leader } \\
\text { Member } \\
\text { Exchange }\end{array}$ & 0,759 & 0,097 & 0,618 & 7,815 & 0,000 \\
\hline
\end{tabular}

\section{Analisis Regresi}

Tabel 7 Uji Regresi

\begin{tabular}{|l|l|l|r|}
\hline Model & \multicolumn{1}{|c|}{ T } & Sig. \\
\hline \multirow{2}{*}{} & (Constant) & 7,234 & 0,000 \\
\cline { 2 - 4 } & LMX & 7,815 & 0,000 \\
\hline
\end{tabular}

Nilai konstanta (a) sebesar 3,681 dengan koefisien regresi (b) sebesar 0,759. Dari hasil tersebut diperoleh model regresi liner sederhana sebagai berikut:

$$
\begin{aligned}
& \mathbf{Y}=\mathbf{a}+\mathbf{b} X \\
& \mathbf{Y}=\mathbf{3 , 6 8 1}+\mathbf{0 , 7 5 9 X}
\end{aligned}
$$

Nilai a dan $b$ diatas dapat diinterpretasikan sebagai berikut: 
1. Konstanta sebesar 3,681 dapat diartikan jika leader member exchange sama dengan nol $(\mathrm{X}=0)$ atau tidak ada leader member exchange, maka kepuasan kerja karyawan hanya sampai nilai sebesar 3,681 .

2. Leader member exchange memiliki nilai koefisien regresi linier sederhana sebesar 0,759. Hal ini mengandung arti bahwa apabila leader member exchange mengalami kenaikan satu satuan maka kinerja karyawan akan mengalami kenaikan sebesar 0,759 satuan.

\section{Koefisien Determinasi}

Tabel 8 Koefisien Determinasi

\begin{tabular}{|l|c|r|r|r|}
\hline Model & $\mathbf{R}$ & $\begin{array}{c}\mathbf{R} \\
\text { Square }\end{array}$ & $\begin{array}{c}\text { Adjusted } \\
\mathbf{R} \\
\text { Square }\end{array}$ & $\begin{array}{c}\text { Std. Error } \\
\text { of the } \\
\text { Estimate }\end{array}$ \\
\hline 1 & 0,618 & 0,382 & 0,375 & 5,861 \\
\hline
\end{tabular}

Nilai koefisien determinasi atau $R$ Square yang diperoleh adalah 0,382 atau $38,2 \%$. Hal ini menunjukan bahwa leader member exchange memberikan kontribusi pengaruh sebesar 38,2\% terhadap kepuasan kerja karyawan sedangkan sisanya $61,8 \%$ dipengaruhi oleh faktor-faktor lain yang tidak diteliti dalam penelitian ini.

\section{KESIMPULAN DAN SARAN Kesimpulan}

Berdasarkan hasil analisis dan pembahasan yang telah dipaparkan, maka dapat ditarik kesimpulan untuk menjawab perumusan masalah seperti berikut ini:

1. Leader member exchange di PT Sandy Globalindo tergolong dalam kategori cukup. Hal ini berdasarkan analisis deskriptif variabel leader member exchange yang memiliki nilai mean sebesar 2,91 yang berada pada skala interval 2,61 - 3,40 dengan standar deviasi 0,325 atau sama dengan $11,16 \%$ dari nilai mean. Dimensi contribution memiliki nilai terendah adalah dengan nilai mean sebesar 2,72 dan yang memiliki nilai tertinggi adalah dimensi professional respect dengan nilai mean sebesar 3,29.

2. Kepuasan kerja karyawan di PT Sandy Globalindo tergolong dalam kategori cukup. Hal ini berdasarkan analisis deskriptif variabel kepuasan kerja yang memiliki nilai rata-rata 3,04 yang berada pada skala interval 2,61 - 3,40 dengan standar deviasi 0,330 atau sama dengan $10,85 \%$ dari nilai mean. Dimensi supervisi memiliki nilai terendah dengan nilai mean sebesar 2,23 dan yang memiliki nilai tertinggi adalah dimensi imbalan dan rekan kerja dengan nilai mean sebesar 3,88.

3. Terdapat pengaruh antara leader member exchange terhadap kepuasan kerja karyawan sebesar 38,2\% berdasarkan nilai R Square. Sedangkan $61,8 \%$ sisanya dipengaruhi hal-hal lain yang tidak dimasukan dalam penelitian ini seperti kedudukan atau jabatan dalam perusahaan, mutu pengawasan, keamanan kerja, penghargaan dan lainnya. Berdasarkan hasil regresi sederhana diperoleh hasil konstanta $(\alpha)$ bernilai 3,681 dengan koefisien regresi (b) 0,759 sehingga muncul persamaan regresi sebagai berikut $\mathrm{Y}=3,681+0,759 \mathrm{X}$. Dari persamaan regresi tersebut, dapat diketahui bahwa setiap penambahan satu angka leader member exchange dengan koefisien regresi bernilai positif, maka kepuasan kerja karyawan akan meningkat sebesar 0,759. Sedangkan, apabila leader member exchange sama dengan nol atau tidak ada perubahan, maka nilai kepuasan kerja karyawan sebesar 3,681. Dengan demikian, jika leader member exchange di PT Sandy Globalindo mengalami peningkatan, maka kepuasan kerja karyawan di PT Sandy Globalindo akan meningkat pula.

\section{Saran}

Berdasarkan kesimpulan dan pembahasan yang telah dipaparkan, maka adapun saran yang diberikan untuk PT 
Sandy Globalindo dalam menekan leader member exchange dan kepuasan kerja karyawan adalah seperti berikut ini:

1. Sebaiknya pimpinan tidak memperlakukan bawahannya dengan berbeda-beda dan melakukan pendekatan kepada setiap bawahan guna mempererat hubungan atasan dengan bawahan dengan cara menggunakan pendekatan otentik dengan hormat dan tegas, mengevaluasi setiap motif, sikap dan sumber daya potensial dari setiap karyawan demi menciptakan tujuan perusahaan.

2. Sebaiknya supervisi pimpinan perusahaan melakukan atau meningkatkan pengawasan kepada karyawan serta melakukan pendekatan kepada karyawannya dengan lebih mengenal pribadi kompetensi karyawan agar mereka merasa dibutuhkan oleh perusahaan, diperhatikan dan dianggap keberadaannya. Selain pimpinan memberikan kesempatan untuk berkembang melalui pelatihan untuk karyawan guna mengembangkan pengetahuan dan keterampilannya.

3. Dalam usaha untuk meningkatkan leader member exchange dapat diterapkan beberapa cara seperti tetap fokus pada tujuan masing-masing departemen, memberdayakan kemampuan diri, meningkatkan hubungan dengan manajer, menggunakan pendekatan otentik, hormat, dan tegas. Sedangkan untuk meningkatkan kepuasan kerja dapat dilakukan dengan melakukan perubahan struktur kerja, melakukan perubahan struktur pembayaran, pemberian jadwal kerja yang fleksibel dan mengadakan program yang mendukung.

\section{DAFTAR PUSTAKA}

Bitmis, M. G., \& Ergeneli, A. (2012). "The Moderating Effect Of Work Stress On The Relationships Between Dimensions of Leader Member Exchange and Job
Satisfaction". Journal of Global Strategic Management. 11, 112-120.

Colquitt, J. A., Jeffrey A., L., \& Michael J. W. (2011). Organizational Behavior. New York: McGraw-Hill

Hwa, A. M. C, Jantani, M., \& Ansari, M. A. (2009). "Supervisor vs. Subordinate Perception on Leader Member Exchange Quality: A Malaysian Perspective". International Journal of Business and Management. 4(7), 165-171.

Luthans, F. (2008). Perilaku Organisasi Edisi Kesepuluh. Alih Bahasa: Vivin Andika Yuwono dkk. Yogyakarta: Andi. Mapolisa, T., \& Kurasha, P. (2013). "Leader-Member Exchange Theory: A Driver For Open And Distance Learning (ODL) Quality Programme Management At The Zimbabwe Open University". International Journal of Asian Social Science. 3(2), 321-333.

McShane, S. L., \& Glinow, M. A. V. (2010). Organizational Behavior. New York: McGraw-Hill.

Mumma, S. (2010). "Student Leader LMX Relationship as Moderated by Constructive-Developmental Theory". Theses, Disertations \& Student Scholarship: Agricultural Leadership, Education \& Communication Department. 9,9-65.

Nurdini, A. (2006). "Cross-Sectional vs Longitudinal": Pilihan Rancangan Waktu dalam Penelitian Perumahan Permukiman". Univrersitas Kristen Petra Vol. 34, No. 1, Juli 2006:52-58.

Prisetyadi, A. (2011). "Pengaruh Leader Member Exchange Terhadap Komitmen Organisasi Pada PT Midian Karya Pasuruan”. Jurnal Manajemen Bisnis. 1(1), 1-6.

Robbins, S. P., \& Judge, T. A. (2015). Perilaku Organisasi: Organizational Behavior. Jakarta: Salemba Empat.

Robbins, S. P., \& Judge, T. A. (2013). Organizational Behavior 15th Edition. New Jersey: Pearson. 
Sugiyono. (2012). Metode Penelitian Wibowo, N. C., \& Sutanto, E. M. (2013). Kuantitatif, Kualitatif dan $R \quad \& \quad D$. "Pengaruh Kualitas Leader Member Bandung: Alfabeta.

Thoha, M. (2007). Perilaku Organisasi: Konsep Dasar dan Aplikasinya. Jakarta: PT Raja Grafindo Persada.

Exchange (LMX) Terhadap

Produktivitas Kerja Melalui Kepuasan

Kerja dan Komitmen Organisasional

Pada PT Nutrifood Surabaya". Agora. 1(1), 1-10. 